\title{
Rosanna Gorris Camos, "Jean Baptiste Giraldy Cynthien Gentilhomme Ferrarois», il Cinthio in Francia
}

\section{Michele Mastroianni}

\section{(2) OpenEdition}

1 Journals

\section{Edizione digitale}

URL: http://journals.openedition.org/studifrancesi/7526

DOI: 10.4000/studifrancesi.7526

ISSN: 2421-5856

\section{Editore}

Rosenberg \& Sellier

\section{Edizione cartacea}

Data di pubblicazione: 1 décembre 2009

Paginazione: 613

ISSN: 0039-2944

\section{Notizia bibliografica digitale}

Michele Mastroianni, «Rosanna Gorris Camos, «Jean Baptiste Giraldy Cynthien Gentilhomme Ferrarois», il Cinthio in Francia», Studi Francesi [Online], 159 (LIII | III) | 2009, online dal 30 novembre 2015, consultato il 08 janvier 2021. URL: http://journals.openedition.org/studifrancesi/7526 ; DOI: https://doi.org/ ERREUR PDO dans /localdata/www-bin/Core/Core/Db/Db.class.php L.34 : SQLSTATE[HY000] [2006] MySQL server has gone away

Questo documento è stato generato automaticamente il 8 janvier 2021.

\section{(c) (i) (9)}

Studi Francesi è distribuita con Licenza Creative Commons Attribuzione - Non commerciale - Non opere derivate 4.0 Internazionale. 
Rosanna Gorris Camos, «Jean Baptiste Giraldy Cynthien Gentilhomme Ferrarois», il Cinthio in Francia

Michele Mastroianni 


\section{NOTIZIA}

ROSANNA GORRIS CAMOS, «Jean Baptiste Giraldy Cynthien Gentilhomme Ferrarois», il Cinthio in Francia, in AA. VV., Giovan Battista Giraldi Cinzio Gentiluomo Ferrarese, a cura di Paolo CHERCHI, Micaela RINALDI e Mariangela TEMPERA, Firenze, Olschki, 2008, pp. 77-129.

1 In questo ricco e denso contributo - vera miniera di notizie erudite e di bibliografia - R. Gorris Camos ripercorre la diffusione francese di Giraldi Cinthio nella seconda metà del Cinquecento, considerando traduzioni ed edizioni dell'autore italiano in Francia, con particolare attenzione alla fortuna editoriale e alla ricostruzione della complessa rete di rapporti della cultura e del mondo politico e religioso d'oltralpe con i centri italiani in cui Giraldi soggiornò e operò (Ferrara, Torino e Mondovì). In questa indagine capillare, l'A. oltre a recensire le traduzioni dei testi giraldiani ricostruisce riferimenti ed echi indiretti. L'attenzione principale, comunque, è rivolta alle traduzioni, degli Hecatommithi anzitutto e dei Dialoghi, con un interessante inquadramento del lavoro di traduttore di Chappuys. Ma la parte più ampia dello studio è consacrata al rifacimento, ad opera di Jean-Edouard Du Monin (autore su cui il saggio offre una vera e propria breve monografia), dell'Orbecche. Tale rifacimento, legato secondo l'A. alla «fitta rete di legami storico-culturali tra la Ferrara del Giraldi e la Parigi de Du Monin, scosse entrambe dallo stesso vento di crisi», si presenta in parte come opera originale a livello anzitutto di topografia testuale, per gli spostamenti interni di scene o mutamenti dell'ordine strutturale, e, a livello stilistico-retorico, con un vero e proprio stravolgimento del modello giraldiano, stravolgimento puntualmente documentato nel corso dell'ampia analisi. 